\title{
Multi-level and Precise Evaluation of Slope Stability in Large Open-pit Mines: a Case Study at Dexing Copper Mine, China
}

\section{Shigui Du}

Ningbo University

Charalampos Saroglou

University of Athens: Ethniko kai Kapodistriako Panepistemio Athenon

\section{Yifan Chen}

Central South University

Hang Lin

Central South University

Yong Rui ( $\nabla$ yongrui@nbu.edu.cn )

Ningbo University https://orcid.org/0000-0003-4703-848X

\section{Research Article}

Keywords: mine slope, shear strength, graded analysis, stability assessment

Posted Date: May 3rd, 2021

DOl: https://doi.org/10.21203/rs.3.rs-409378/v1

License: (c) (1) This work is licensed under a Creative Commons Attribution 4.0 International License. Read Full License 


\section{Multi-level and precise evaluation of slope stability in large 2 open-pit mines: a case study at Dexing Copper Mine, China}

3
Shigui Du ${ }^{1}$

\author{
Shi-Gui Du ${ }^{1}$, Charalampos Saroglou ${ }^{2,3}$, Yifan Chen ${ }^{4}$, Hang Lin ${ }^{4}$, Rui Yong*1 \\ 1 School of Civil and Environmental Engineering, Ningbo University,
} Ningbo, Zhejiang, 315211, P.R. China

2 School of Civil Engineering, National Technical

University of Athens, 15773 Athens, Greece

3 School of Earth Sciences, University of Leeds, Leeds, LS2 9JT UK

4 2School of Resources and Safety Engineering, Central South University,

Changsha, Hunan, 410083, P.R. China

1 School of Civil and Environmental Engineering, Ningbo University, Ningbo, Zhejiang, 315211, P.R. China

Email:dushigui@nub.edu.cn

orcid 0000-0002-0281-488X

Charalampos Saroglou ${ }^{2,3}$

2 School of Civil Engineering, National Technical

University of Athens, 15773 Athens, Greece

3 School of Earth Sciences, University of Leeds, Leeds, LS2 9JT UK

Email:saroglou@central.ntua.gr

orcid 0000-0002-5253-7972

Yifan Chen ${ }^{4}$

4 2School of Resources and Safety Engineering, Central South University,

Changsha, Hunan, 410083, P.R. China

Email:1051361824@qq.com

Hang Lin $^{4}$

4 2School of Resources and Safety Engineering, Central South University,

Changsha, Hunan, 410083, P.R. China

Email:linhangabc@126.com

orcid 0000-0002-5924-5163

Rui Yong*1

1 School of Civil and Environmental Engineering, Ningbo University, Ningbo, Zhejiang, 315211, P.R. China

* Corresponding author (e-mail: yongrui@ @nbu.edu.cn)

orcid 0000-0003-4703-848X 
41 Abstract: As the mining industry developed significantly in the last decades and the depth of open-pit mining has increased, the stability of large open-pit slopes has become a major problem directly related to the safety production and development of a mine. However, the overall slope is indeed safer than the local slope based on the existing stability estimation methods. So the existing methods of directly analyzing the stability of the overall slope will produce some errors in the calculation results of the safety factor, and cannot comprehensively reflect the stability of the mine slope. Based on these problems, this paper adopted the idea of gradual analysis and the precise determination of discontinuity properties to perform a limit equilibrium analysis for the evaluation of mine slope stability. A case study slope, referred to as Yangtaowu Slope in Dexing Copper Mine, was selected for the demonstration of the accuracy of this approach. The results indicate that the adopted method can accurately reflect the actual stability of the slope, especially when the mine slope is near the critical state of stability.

Keywords: mine slope; shear strength; graded analysis; stability assessment 


\section{Introduction}

The calculation and determination of slope safety factor is a significant component for slope stability analysis. With the use of computer technology, numerical simulation has become the predominant approach to calculate the factor of safety of slopes. New methods for calculating the safety factor have been proposed, from qualitative analysis to semi-quantitative analysis, to quantitative analysis, from the limit equilibrium method (Cheng et al., 2007; Lam and Fredlund, 1993; Wei and Cheng, 2010; Wei et al., 2009) to strength reduction method (Lin et al., 2013; Shen and Karakus, 2014), to gravity increase method (Li et al., 2009). Recently, slope stability analysis using a double reduction method was proposed (Bai et al., 2014; Chen et al., 2020; Deng et al., 2017). Irrespectively of what method is proposed, the purpose is to determine the slope stability accurately (Johari et al., 2013; Tang et al., 2016). Yin et al. (2020) have proposed a precise evaluation method for the stability analysis of multi-scale slopes by establishing numerical models of slopes with various scales as well as different grid shapes and sizes to conduct stability analysis.

However, one common assumption made in most of the existing slope stability analysis methods is that the physical model adopted for calculation has a regular geometry with materials characterized by isotropic behavior. To a certain extent, this assumption weakens the difference between the calculation model and the strength parameters in the stability of the mine slope, which leads to inaccuracies. This assumption could lead to an unreliable geometrical model and potential slip surface, as well as inaccuracies in the determination of strength parameters, and ultimately, inaccuracies in computing the safety factor of a slope. Chen and Dubey (2003) pointed out that if the model corresponds closely to the process we can safely infer the process's behavior from the model's behavior. Shi et al. (2004) emphasized that only the accurate calculation could reflect the stability of mine slope correctly. Du et al. (2017) considered that the spatial locations and scales of rock discontinuities have various influences on different types of mine slopes due to the controlling effect of rock mass structure and proposed a graded analysis method for the stability assessment of open-pit mine slopes. 
The same authors noted that the spatial locations of rock discontinuities should match the corresponding part on the slope and the rock joint scale should match the slope scale, which could provide the necessary conditions for accurately evaluating the slope stability of large open-pit mines. To improve the accuracy of stability calculation via controlling the geometric error and calculation error, Du (2018) proposed the equal accuracy assessment method for slope stability of large open-pit mines. To evaluate accurately the slope stability, this paper adopted the idea of graded analysis and the precise evaluation technology of discontinuities for slope stability analysis.

A typical case of a slope in the Dexing Copper Mine, called Yangtaowu slope, was selected for verification of the accuracy of the proposed method. Initially, the global and local stability of the mine slope were analyzed by graded analysis, and the failure mode of the mine slope, as well as the potentially unstable slopes, was determined. Also, the potential slip surface and its potential slip direction were determined, and the accurate calculation model of the slope was established. Later the precise strength parameters of the potential sliding surface in the slip direction were obtained using the precise evaluation technique of the rock mass. Finally, the slope safety factor was calculated by the Morgenstern-Price method, and the results were compared with the existing method under the same conditions. The accuracy of the adopted method was proved, providing an important reference for the accurate decision, design and exact construction of the unstable slope.

\section{Methodology}

\subsection{Graded analysis for slope stability assessment}

The Technical Code (GB 51016-2014 2014) points out that the calculation method and parameter determination of slope stability should be based on the analysis of slope failure mode. The failure mode is determined according to the geological interface, the type of geological structure and its spatial combination. Only through the research based on the characteristics of rock mass discontinuity and the graded study of slope structure can the key discontinuity and its combination, which control slope stability, be found out systematically and a reasonable geo-mechanical model can be provided for slope stability analysis. Therefore, 
in the evaluation of slope stability for large open-pit mines, the influence of different positions and different sizes of structures on slope stability should be taken into consideration. The graded stability analysis of mine slope must be carried out to determine the global stability and local stability.

The spatial locations of rock joints should match the corresponding part on the slope, and the rock joint scale should match the slope scale. According to the matching performance on the relative spatial locations and sizes, the stability of the overall slope, composite-bench slopes and all single bench slopes were systematically analyzed to find out the key joints and their combinations. Based on systematic, detailed field investigation and accurate description, the graded analysis of large open-pit mine slope stability is a process of analyzing slope stability by stratification and determination of the failure model. The stabilities of the entire slope, the combined bench slopes and the single bench slopes can be analyzed from global and local aspects. The graded analysis includes mainly three levels of analysis:

1. Level I: The stability analysis of the overall slope.

Based on the slope grade and scale, determined by the global mine slope design, the discontinuities developed in the rock mass of the slope are classified. Bedding, foliation, schistosity planes and fault structures whose scale is greater than or equal to $m$ multiples of the overall slope size are regarded as penetrating discontinuities ( $m$ is the coefficient of penetration rate and values range from 0.85 to 0.95$)$. The remaining fault structures are regarded as non-penetrating discontinuities and joints are regarded as discontinuities with small scale. According to the dipping direction and dipping angle of the global mine slope, as well as that of the penetrating discontinuities, the stereonet projection is used to analyze the global stability and determine the global failure mode of the mine slope. Similarly, the local stability and the local failure mode of mine slope should also be analyzed based on the stereonet of the non-penetrating discontinuities and the small-scale discontinuities.

2. Level II and III of graded analysis are the combined bench slope stability analysis and the bench slope stability analysis, respectively.

The analysis method is the same as that of level I, but the analyzing objects are changed from the overall slope to the combined bench slope and the bench slope.

Graded analysis can not only qualitatively analyze the potential failure mode of slope, it 
also determines the sampling object for precise value of shear strength of discontinuities and provides an objective and accurate geometric model for precise stability evaluation of large open-pit mine slope.

\subsection{Accurate assessment of geometry and shear strength of structure planes}

The assessment of discontinuity properties is of great importance on controlling the structural stability of slopes. The determination of the shear strength parameters of rock mass discontinuity has a significant impact on the slope stability calculations.

The shear strength of the sliding surface of mine slope is suggested to be carried out according to the following steps:

(1) Identify the study object, which means finding the potential sliding surface based on the mine slope stability graded analysis.

(2) Slip direction analysis. Due to the existence of anisotropy (Xie et al., 2020; Du and Tang, 1993), only the shear parameters along the slip direction of rock mass discontinuity reflect the shear strength of the slope.

(3) Discontinuity measurement. With the assistance of measuring instruments, the joint compressive strength (JCS) of the joint walls is measured in situ and the roughness is measured in a certain orientation.

(4) JRC statistical analysis. The roughness coefficient of the surface contour curve of the discontinuity is calculated and statistically analyzed (Yong et al., 2017).

(5) The analysis of the scale effect of JRC. The relationship between JRC and joint size was obtained, and the value for engineering practice can be determined (Barton and Bandis, 1980; Yong et al., 2018a).

(6) Rebound data analysis of discontinuity. The joint compressive strength (JCS) of the discontinuity can be determined according to the relationship between the rebound value and the strength of the joint compressive strength. Based on the quantitative relationship of the rebound value and the basic friction angle, it is easy to determine the basic friction angle and the residual friction angle of the discontinuity. 


\subsection{Presence of faults}

For those slopes that their stability is controlled by fault structures, it is not reasonable to use the same approach for slope stability as in the case that the slope stability is controlled by the quality of rock mass. To evaluate the stability of slopes with intersecting faults, it is necessary to give priority to the influence of controlling faults. Thus, an accurate slope stability model must be established based on the location, geometry and trace length of fault structures (here discontinuities). The stability analysis is controlled by the structural features, such as fault planes, and thus the stability is calculated using non-circular failure surfaces.

\section{Case study: Yangtaowu Slope at Dexing Copper Mine, China}

\subsection{General}

Dexing Copper Mine is located in Dexing City, Jiangxi Province, China, with a total area of 37 square kilometers. Its design boundary is $2300 \times 2400 \mathrm{~m}^{2}$, as shown in Fig. 1. The total surface area of the mine is $100 \mathrm{~km}^{2}$, with 1.63 billion tons of proven copper ore reserves and 1.32 billion tons of present copper ore reserves, as well as 5 million tons of copper metals. Dexing Copper Mine, the main mine of Jiangxi Copper Industry Group Company, is the largest opencast copper mine in China and the largest opencast copper mine in Asia, which is also one of several super-large porphyry copper mines in the world.

Following continuous mining, the mining area has been divided into the mine slopes of Yangtaowu, Shuilongshan, Shijinyan, Niuqian and Xiyuanling. These slopes were designed with the height ranging between $200 \mathrm{~m}$ and $700 \mathrm{~m}$ in height. According to the experience of open-pit mine, the mine slope stability decreases while the potential threat increases when the vertical height of the slope is over $200 \mathrm{~m}$. For such a large-scale open-pit mine, the precise study of slope stability is an important and arduous work, which is of great significance to ensure the safety of mine production, to design the optimal slope angle, and to improve economic benefits. 
Yangtaowu Slope in Dexing Copper Mine was selected as a case study in this paper. The slope, striking near east-west and dipping to north, has a height of $290 \mathrm{~m}$, a width of $210 \mathrm{~m}$, a slope direction of $10^{\circ}$ and a slope angle of $30^{\circ}$, with heterogeneous metamorphic rocks exposed. Due to the influence of gravity, faults, joints and other factors such as blasting vibration and groundwater, local instability has already occurred in some sections of the slope during the process of mining.

According to the parameters variation of slope engineering, Yangtaowu Slope can be divided into three main parts from bottom to top (as shown in Fig. 2): The $-10 \mathrm{~m}$ combined bench slope (composed of three slopes of A(-10T), B (-10T) and C (-10T), which are located in the east, the middle and the west of the $-10 \mathrm{~m}$ combined bench slope, respectively); The 50 m combined bench slope (composed of two slopes of A (50T) and B (50T), which are located in the east and west of the $50 \mathrm{~m}$ combined bench slope, respectively); The $110 \mathrm{~m}$ composite bench slope. The field investigation found that 6 faults exist in the slope. The joints were extremely developed, resulting in the fractured rock mass. Additionally, the characteristics of fault and joints were listed in Table 1.

\subsection{Graded analysis on slope stability}

3.3.1 Level I of graded analysis to Yangtaowu Slope: The overall slope stability analysis

(1) Global stability analysis

There develops a penetrating surface extending along foliation face and cleavage face within the overall slope. As shown in Fig. 3, it is found that the slope direction is $10^{\circ}$ and the slope angle is $30^{\circ}$. The occurrence of fault $\mathrm{F} 7$ is $346^{\circ} \angle 43^{\circ}$, with an inclination crossing angle of $24^{\circ}$ between F7 and the overall slope. The strike of F7 is consistent with the overall slope, but the dip angle of F7 is greater than that of the overall slope. As a result, the overall slope is basically stable.

(2) Local stability analysis

The mine slope investigation focused on the stabilities of $-10 \mathrm{~m}$ combined bench slopes, 
thus no systematically all-around investigation of the overall slope was carried out for analyzing the local stability of the overall slope in this study.

3.3.2 Level II of graded analysis to Yangtaowu Slope: The combined bench slope stability analysis

The $-10 \mathrm{~m}$ combined bench slope is located between $-10 \mathrm{~m}$ platform and $50 \mathrm{~m}$ platform within Yangtaowu overall slope. The $20 \mathrm{~m}$ platform, formed by the planned mining, divides the combined bench slope into two sections. The slope angle of the upper bench slope (i.e. UP) is $52^{\circ} \sim 59^{\circ}$. The slope angle of the lower step slope (i.e. DOWN) is $51^{\circ} \sim 53^{\circ}$. The direction of $\mathrm{A}(-10 \mathrm{~T}), \mathrm{B}(-10 \mathrm{~T})$ and $\mathrm{C}(-10 \mathrm{~T})$ combined bench slope are $6^{\circ}, 350^{\circ}$ and $16^{\circ}$, respectively. There are four faults (fault F1, fault F2, fault F3, fault F4) and three groups of joints (joint J1, joint $\mathrm{J} 2$, joint J3), within the $-10 \mathrm{~m}$ combined bench slope. The pump station for water drainage at the pit bottom has been set up on the bottom of the $-10 \mathrm{~m}$ platform. Furthermore, only B(-10T) combined bench slope (i.e. B (-10T) in brief) was selected to be an example to conduct stability analysis via precise evaluation in this paper. The location of B (-10T) is shown in Fig. 4.

(1) Global stability analysis

As the penetrating discontinuity of the slope, faults control the global stability of the B (-10T). It can be seen from Fig. 5 that the slope direction of the B $(-10 \mathrm{~T})$ is $350^{\circ}$ and the slope angle is $47^{\circ}$. The occurrence of fault $\mathrm{F} 2$ is $345^{\circ} \angle 45^{\circ}$, with an inclination crossing angle of $5^{\circ}$ between F2 and $\mathrm{B}(-10 \mathrm{~T})$. The occurrence of fault F3 is $347^{\circ} \angle 42^{\circ}$, with an inclination crossing angle of $3^{\circ}$ between F3 and B (-10T). The strikes of F2 and F3 are both consistent with the B (-10T), but the dip angles of F2 and F3 are smaller than that of the B (-10T). Therefore, it is likely for the B (-10T) to have single plane slip failure occurred along F2 or F3. Besides, there is also a group of penetrating joint $\mathrm{J} 1$ inclining to the inside of the $\mathrm{B}(-10 \mathrm{~T})$, with the occurrence of $103^{\circ} \angle 86^{\circ}$ and an inclination crossing angle of $113^{\circ}$ between $\mathrm{J} 1$ and $\mathrm{B}$ (-10T). Although the B (-10T) is stable under the influence of the penetrating joint $\mathrm{J} 1$, it provides the cutting boundary for slope, increasing the possibility of single plane slip failure. From the above, it is highly possible for the $\mathrm{B}(-10 \mathrm{~T})$ to take $\mathrm{J} 1$ as the cutting boundary and have the single plane slip failure occurred along F2 or F3. 
(2) Local stability analysis

Joint, though with small scale, share the control of the local stability of the combined bench slope with the penetrating discontinuity such as faults.

As shown in Fig. 6, the local stability of B (-10T) is controlled by fault F2, F3, penetrating joint $\mathrm{J} 1$ and non-penetrating joint $\mathrm{J} 2$. The slope direction is $350^{\circ}$ and the slope angle is $47^{\circ}$. The B (-10T) has faults F2 and F3 developed. And the occurrence of fault F2 is $345^{\circ} \angle 45^{\circ}$, with an inclination crossing angle of $5^{\circ}$ between F2 and B (-10T). The occurrence of fault F3 is $347^{\circ} \angle 42^{\circ}$, with an inclination crossing angle of $3^{\circ}$ between F3 and B (-10T). The strikes of F2 and F3 are both consistent with the B (-10T), but the dip angles of F2 and F3 are smaller than that of the B (-10T). As a result, it is possible for the B (-10T) to have single plane slip failure occurred along F2 or F3. There is also a group of penetrating joint J1 inclining to the inside of the B (-10T), with occurrence of $103^{\circ} \angle 86^{\circ}$ and an inclination crossing angle of $113^{\circ}$ between $\mathrm{J} 1$ and $\mathrm{B}(-10 \mathrm{~T})$, and a group of non-penetrating joints $\mathrm{J} 2$, with occurrence of $281^{\circ} \angle 69^{\circ}$ and an inclination crossing angle of $69^{\circ}$ between $\mathrm{J} 2$ and $\mathrm{B}$ (-10T). It is easy to conclude it is impossible for the local slip failure to occur along $\mathrm{J} 2$ for joint angle of $\mathrm{J} 2\left(69^{\circ}\right)$ is greater than the slope angle $\left(47^{\circ}\right)$.

Although the B (-10T) is locally stable under the influence of the non-penetrating joint $\mathrm{J} 2$, it provides the cutting boundary for slope, increasing the possibility of single plane slip failure along fault $\mathrm{F} 2$ and $\mathrm{F} 3$. From the above, it is highly possible for the $\mathrm{B}(-10 \mathrm{~T})$ to take $\mathrm{J} 2$ as the cutting boundary and have the single plane slip failure occurred along F2 or F3. And the local stability is similar to the global stability of B(-10T).

\subsubsection{Level III of graded analysis to Yangtaowu Slope: The bench slope stability analysis}

The combined bench slopes B(-10T) was selected to conduct the bench slope stability analysis. The upper and lower bench slopes of the B (-10T) were named as B (-10T)-U, B (-10T)-D for convenience.

(1) Global stability analysis

Foliation has developed within the B(-10T)-U and B(-10T)-D, in which there are two penetrating faults (i.e. F2 and F3) developing and extending along the foliation. F2 and F3 have a similar occurrence with the foliation. From the analysis of stereographic projection 
(Fig. 7), it is similar to the failure mode of B (-10T), B (-10T) -U and B (-10T) -D are both likely to be cut off by joint $\mathrm{J} 1$ and have the single plane slip failure occurred along fault F2 or F3.

(2) Local stability analysis

Fig. 8 shows the local stability of B(-10T)-U and B(-10T)-D is controlled by fault F2, fault F3, penetrating joint $\mathrm{J} 1$ and non-penetrating joint $\mathrm{J} 2$. And the local stability of bench slope is similar to that of global stability, that is, B (-10T) -U and B (-10T) -D are both likely to be cut off by joint $\mathrm{J} 2$ and have the single plane slip failure occurred along fault F2 or F3.

\section{Stability assessment of Yangtaowu Slope}

\subsection{Precise evaluation of geometry and shear strength of structure planes}

Taking the B(-10T) slope as an example, the shear strength parameters were determined. The results of graded analysis illustrate that it is of great possibility for the $\mathrm{B}(-10 \mathrm{~T})$ to have single plane slip failure occurred along fault F2 and F3. The fault F2 and F3 are basically the same in lithology and occurrence, with close spatial position and alike rough and undulating characteristics, and they have similar physical and mechanical properties. Therefore, fault F2 was select to investigate the precise value of the shear strength of discontinuity.

(1) Precise sampling of discontinuity for JRC measurement

In the field, the measuring lines were uniformly arranged with $10 \mathrm{~cm}$ as the interval along the inclination direction on the surfaces of fault F2, and 35 surface contour curves of $40 \mathrm{~cm}$ in length were plotted using the profilometer (as shown in Fig. 9a) (Yong et al., 2018b). The recorded joint profiles are tabulated in Table 2. A large-scale engineering scanner was used to scan the drawings of the contour curves of the discontinuity and convert them into picture format texts.

Based on the morphological filtering denoising and image normalization method (Yong et al., 2017), MATLAB was used to extract the scanning drawing of the contour curves of the discontinuity according to the gray value. Using the relationship between the actual length of the discontinuity and the size of the digitized matrix of the graph, the coordinate data of each 
profile curve at $0.5 \mathrm{~mm}$ spacing were automatically read and stored.

Then the roughness coefficients of the surface contour curves were calculated and statistically analyzed by adopting the sampling length of $L_{1}=10 \mathrm{~cm}, L_{2}=20 \mathrm{~cm}, L_{3}=30 \mathrm{~cm}$, $L_{4}=40 \mathrm{~cm}$ for each contour curve, respectively. The calculation results are tabulated in Table 3.

According to the JRC measurement results, the average values of JRC with sampling length of $10 \mathrm{~cm}, 20 \mathrm{~cm}, 30 \mathrm{~cm}, 40 \mathrm{~cm}$ were obtained, denoting as $\mathrm{JRC}_{1}, \mathrm{JRC}_{2}, \mathrm{JRC}_{3}, \mathrm{JRC}_{4}$, respectively. The result is shown in Table 4 .

(2) Determination of fractal dimension of JRC considering size effect

Du et al. (2015) proposed the JRC fractal Model considering scale effect as follows :

$$
J R C_{n}=J R C_{1}\left(\frac{L_{n}}{L_{1}}\right)^{-D}
$$

Then, the fractal dimension of JRC can be expressed as follows:

$$
D=\frac{\lg \left(J R C_{1} / J R C_{n}\right)}{\lg \left(L_{n} / L_{1}\right)}
$$

Where $n=2,3,4$.

Considering scale effect, the fractal dimensions of the roughness coefficient (i.e. $D_{1}, D_{2}$, $\left.D_{3}, D_{4}\right)$ were obtained via Eq. (2). Then, the predicted fractal dimension $D_{n}{ }^{*}$ of JRC, was calculated by Eq. (3) considering the weight value of $D_{2}, D_{3}$ and $D_{4}$ in size.

$$
D_{n}^{*}=\frac{L_{2}-L_{1}}{L_{2}-L_{1}+L_{3}-L_{1}+L_{4}-L_{1}} D_{2}+\frac{L_{3}-L_{1}}{L_{2}-L_{1}+L_{3}-L_{1}+L_{4}-L_{1}} D_{3}+\frac{L_{4}-L_{1}}{L_{2}-L_{1}+L_{3}-L_{1}+L_{4}-L_{1}} D_{4}
$$

The predicted value was considered approximately equal to the actual value, then $D_{n}{ }^{*}$ could be represented by $D_{n}$. The calculated $D_{n}$ of calculation results of fault F2 is 0.214 .

(3) Determination of effective sampling length of the discontinuities

In previous studies, the scale effect of joint roughness was found by many researchers. JRC generally decreases with the increase of discontinuity size, and it remains stable when the sample size exceeds a certain length (Fardin et al., 2001). The size is called the stable threshold length of $J R C$, which is labeled as $L_{n}{ }^{*}$. Defining $f$ as the coefficient of JRC size effect when sampling length is $L_{n}$ (Du et al., 2015). The relation curves between $f$ and $L_{n}$ of fault F2 are plotted in Fig. 10. 


$$
f=\frac{\left(0.1 L_{n}\right)^{-D_{n}^{*}}-\left(0.1 L_{n}-1\right)^{-D_{n}^{*}}}{2^{-D_{n}^{*}}-1}
$$

In Fig. 10, it indicates that when $f=0.05$, the $L_{n}$ equals to $170 \mathrm{~cm}$. Thus, the effective sampling length of fault F2 was $170 \mathrm{~cm}$.

(4) Determination of the predicted value of joint roughness coefficient of actual discontinuity According to the actual value of $D_{\mathrm{n}}$ and the sampling length $L_{\mathrm{n}}=170 \mathrm{~cm}$ of fault F2, the $\mathrm{JRC}_{\mathrm{n}}$ of discontinuity with actual dimension were obtained based on Eq.1. Therefore, the $\mathrm{JRC}_{\mathrm{n}}$ of potential slip plane corresponding to $\mathrm{F} 2$ was 5.883 .

(5) Determination of the JCS of the discontinuity

On the potential slip surface (fault F2), at least 16 points were measured by the Schmitt rebound apparatus (as shown in Fig. 9b). The maximum 3 values and the minimum 3 values were eliminated, and the arithmetic mean of the residual rebound value was calculated. Note that, the measuring points should avoid voids, peeling and edge when measuring. In Table 5, the rebound values of fault F2 are mainly distributed in a range of $40 \mathrm{MPa}$ to $48 \mathrm{MPa}$. The calculated JCS value of fault F2 based on the average rebound values was $41.7 \mathrm{MPa}$. Considering a series of severe typhoon rainstorms, the rock mass in the mine slope was wet and saturated. Therefore, the measured rock mechanical parameters reflected the basic mechanical properties of rock under a saturated state.

According to the relation between the rebound value and the joint compressive strength proposed by Deere and Miller (1966), the joint compressive strength value of fault F2 was 81.99 MPa when its weight was adopted as $25 \mathrm{kN} / \mathrm{m}^{3}$. Under the saturated condition, $\mathrm{JCS}_{\mathrm{n}}$ of fault F2 and F4 were calculated to be 33.05 MPa based on Eq. 5.

$$
J C S_{n}=J C S_{1}\left(\frac{L_{n}}{L_{1}}\right)^{-1.5 D}
$$

\section{(6) Determination of residual friction angle of discontinuity}

Based on the linear relationship between rebound value and the basic friction angle of the discontinuity (Chen et al., 2005), the basic friction angles of potential slip plane obtained as $26.54^{\circ}$ for fault $\mathrm{F} 2$.

$$
\phi_{b}=0.414 N+9.273
$$


Here, the global stabilities of combined bench slope B (-10T) were calculated as an example to show the slope stability precise evaluation.

Based on the detailed investigation of $\mathrm{B}(-10 \mathrm{~T})$ and the result of the total station orientation survey, the geometric model of B(-10T) was obtained, which is shown in Fig. 11a. The generalization calculation model is shown in Fig. 11b. The calculation parameters of $\mathrm{B}(-10 \mathrm{~T})$ are shown in Table 11 . The stability of $\mathrm{B}(-10 \mathrm{~T})$ was analyzed by the existing generalized stability evaluation method and the precise evaluation method, and the safety factor of $\mathrm{B}(-10 \mathrm{~T})$ was calculated under the influence of the most unfavorable factors of saturation, fissure water, gravity and blasting vibration. According to the actual situation of Dexing Copper Mine and the reference of the experience of similar mines in China and elsewhere, the equivalent vibration acceleration coefficient of 0.0392 was adopted. The calculated safety factors are shown in Table 7.

The calculated results illustrate that the safety factors of $\mathrm{B}(-10 \mathrm{~T})$ are both less than 1.05 under the most unfavorable condition, for both the precise or the traditional generalized evaluation method. The evaluation results are consistent with each other. The slope $\mathrm{B}(-10 \mathrm{~T})$ is unstable and will fail under the most unfavorable working conditions.

In fact, on November 6,2014 , the slope of $\mathrm{B}(-10 \mathrm{~T})$ had the first larger-scale slide occurred (i.e. B1, in brief), the sliding area was up to $1451 \mathrm{~m}^{2}$ and the volume of the sliding body was $3550 \mathrm{~m}^{3}$. The precise evaluation result is consistent with the actual slope stability, which also proves the validity and correctness of the precise evaluation method.

After the first evaluation, the slope surface of B (-10T) had changed and the potential slip surface had turned from fault F2 to F3. In order to ensure the safety of life and property, it is necessary to evaluate the stability of $\mathrm{B}(-10 \mathrm{~T})$ again. The calculating geometry model was obtained as shown in Fig. 12a. The generalization calculation model is shown in Fig. 12b. The stability of $\mathrm{B}(-10 \mathrm{~T})$ was also analyzed under the most unfavorable conditions by the traditional generalized evaluation method and the precise evaluation method. The calculated safety factors are shown in Table 7. 
The results of the second stability calculation show that the calculated safety factor of the precise evaluation method is 1.061 , greater than 1.05 . The stability is weak, but the slope will not fail without any other influences. While the calculated safety factor of the traditional generalized evaluation method is 0.904 and the failure must occur. The evaluation results of two methods deviate from each other. Actually, the slope of $\mathrm{B}(-10 \mathrm{~T})$ was stable at that time, which reflected the accuracy of precise evaluation method again.

However, the precise evaluation result is quite close to 1.05 , which means $\mathrm{B}(-10 \mathrm{~T})$ is vulnerable to other influences, resulting in the slope failure. To eliminate the threat of potential sliders on the safety of construction personnel and equipment at fixed pumping stations, on March 15, 2016, slope workers planned to cut the lower part of the B(-10T) by blasting. The third stability evaluation was carried out. The geometric model, calculation parameters and calculation method adopted were same as the second evaluation. The calculation models are shown in Fig.13, and the third evaluation results were shown in Table 7.

Table 7 indicates that experiencing blasting cutting, the safety factor of $\mathrm{B}(-10 \mathrm{~T})$, calculated by the precise evaluation method, reduces to 1.026. It indicates that the slope failed after the excavation. In fact, the second large-scale slide of $\mathrm{B}(-10 \mathrm{~T})$ occurred after unloading (i.e. B2, in brief), the sliding area was up to $1035 \mathrm{~m}^{2}$, and the slip body was $3200 \mathrm{~m}^{3}$. The comprehensive comparison of stability calculation results of $\mathrm{B}(-10 \mathrm{~T})$ before and after excavation (i.e. the second and the third evaluation results) with the actual stability was made, and it can be deduced that, compared to the existing evaluation method, the precise evaluation method is more accurate in calculating the safety factor, and it is able to reflect slope stability more truthfully.

The locations of these slopes are as shown in Fig. 14, and different colors correspond to different slopes. The dark yellow and red arrows represent the first and second landslides (B1 and B2), respectively. The bright yellow rectangle is the location of residual slope B. The cyan rectangle was unloaded on the slope foot. It can be seen from Fig. 19 that the residual slope B is located between B1 and B2, and the slope surface is just the sliding surface of B2. Besides, big security risks may exist due to the intersection of fault F2 and F3. In order to 
ensure the safe operation of the fixed pumping station below, it is necessary to obtain the accurate stability of the residual slope B.

According to the field investigations, it is very likely that the residual slope B will be cut off by $\mathrm{J} 1$ as the cutting boundary, and have the single plane slip failure occurred along the fault F2. The calculation model of the residual slope B is shown in Fig. 15. The results of the stability calculation are shown in Table 7.

As Table 7 illustrates that the safety factor of the residual slope B is greater than 1.05 even under the most unfavorable working conditions, with weak stability. But it will not fail if only influenced by the current impact factors. Under the same conditions, the calculated result of the existing generalized method is 0.967 , less than 1.05 , which indicates that the residual slope B has already failed. In fact, the residual slope B is still in a stable state at present and there is no incident of landslide, which is consistent with the precise evaluation result and contrary to the generalization evaluation results. The comparison between the prediction and the actual situation further shows the correctness and superiority of the precise evaluation method in calculating the safety factor of slope.

\section{Conclusions}

Accurate, reasonable geometric models and precise, credible strength parameters are the basis of slope stability evaluation. An ideal condition is to have available a complete understanding of the characteristics of all the elements of the slope. However, due to the uncertainty of a rock mass, and the limitation of surveying technology, as well as the subjective experience, the stability analysis of a slope in large open-pit mines is often carried out by a general approach using numerical simulation methods. The slope surface and potential slip plane are considered linear, and the rock strength parameters are determined by rock strength reduction, which may have a significant difference compared to the actual parameters, leading to significant errors in the process of modeling and the slope stability results.

(1) Based on the engineering characteristics, Yangtaowu slope was analysed at three levels: the overall slope, the combined bench slope and the bench slope. According to the 
graded analysis results, the overall slope proved globally stable. The global and local stabilities of combined bench slope B(-10T) are both weak. The bench slopes B (-10T)-U and B (-10T)-D are still stable.

(2) Taking B (-10T) as an example, accurate strength parameters of slope discontinuities were obtained based on the accurate assessment of shear strength of structure planes. The discontinuity geometry of $\mathrm{B}(-10 \mathrm{~T})$ was recorded by joint roughness profilometer. Based on morphological filtering and denoising, using image normalization and global search, the roughness coefficient of the discontinuity surface contour curve was calculated and statistically analyzed. According to the relationship between JRC with sample size, the stability threshold of JRC was determined. Then the joint compressive strength and residual friction angle were obtained, and the discontinuity roughness coefficient and the joint compressive strength were calculated when the discontinuity size reaches the threshold.

(3) Based on the stability graded analysis of rock slope and accurate assessment of geometry and shear strength of structure planes, the stability precise evaluation based on Morgenstern-Price method was conducted in slope B(-10T). The comparison of the calculated results with slope history and the current state now indicated that the precise evaluation method could evaluate the stability of mine slope more correctly and accurately.

Acknowledgments: The study was funded by the National Natural Science Foundation of China (Nos. 41502300, 41427802, and 41572299), Zhejiang Provincial Natural Science Foundation (No. LQ16D020001).

461 


\section{References:}

Bai B, Yuan W, Li XC (2014) A new double reduction method for slope stability analysis. Journal of Central South University 21:1158-1164. https://doi.org/10.1007/s11771-014-2049-6

Barton N, Bandis S (1980) Some effects of scale on the shear strength of joints. International Journal of Rock Mechanics and Mining Science \& Geomechanics Abstracts 17:69-73. https://doi.org/10.1016/0148-9062(80)90009-1

Chen Y, Dubey VK (2003) Accuracy of Geometric Channel-Modeling Methods. IEEE Transactions on Vehicular Technology 53:82-93. https://doi.org/10.1109/TVT.2003.821999

Chen Y, Lin H, Cao R, Zhang C (2020) Slope Stability Analysis Considering Different Contributions of Shear Strength Parameters. International Journal of Geomechanics 21: 04020265. https://doi.org/10.1061/(ASCE)GM.1943-5622.0001937

Chen Z, Wang X, Yang J, Jia Z, Wang Y (2005) Rock slope stability analysis: Theory, methods and programs. China Water Power Press, Beijing (in Chinese)

Cheng YM, Lansivaara T, Wei WB (2007) Two-dimensional slope stability analysis by limit equilibrium and strength reduction methods. Computers and Geotechnics 34:137-150. https://doi.org/10.1016/j.compgeo.2006.10.011

Deere D, Miller R (1966) Engineering classification and index properties for intact rock. Dissertation, University of Illinois at Urbana

Deng DP, Li L, Zhao LH (2017) Limit equilibrium method (LEM) of slope stability and calculation of comprehensive factor of safety with double strength-reduction technique. Journal of Mountain Science 14:2311-2324. https://doi.org/10.1007/s11629-017-4537-2

Du SG (2018) Method of equal accuracy assessment for the stability analysis of large open-pit mine slopes. Chinese Journal of Rock Mechanics and Engineering 37:1301-1331 (in Chinese)

Du SG, Tang HM (1993) Anisotropy of roughness coefficient of fracture rock. Journal of Engineering Geology 1: 32-42 (in Chinese)

Du SG, Gao HC, Hu YJ, Huang M, Zhao H (2015) A New Method for Determination of Joint Roughness Coefficient of Rock Joints. Mathematical Problems in Engineering 2015:1-6. https://doi.org/10.1155/2015/634573

Du SG, Yong R, Chen JQ, Xia CC, Li GP, Liu WL, Liu YM, Liu H (2017) Graded analysis for slope stability assessment of large open-pit mines. Chinese Journal of Rock Mechanics and Engineering (in Chinese)

Fardin N, Stephansson O, Jing L (2001) The scale dependence of rock joint surface roughness. International Journal of Rock Mechanics and Mining Sciences 38:659-669. https://doi.org/10.1016/S1365-1609(01)00028-4

Johari A, Fazeli A, Javadi AA (2013) An investigation into application of jointly distributed random variables method in reliability assessment of rock slope stability. Computers and Geotechnics 
Lam L, Fredlund DG (1993) A general limit equilibrium model for three-dimensional slope stability analysis. Canadian Geotechnical Journal 30:905-919 https://doi.org/10.1139/t93-089

Li LC, Tang CA, Zhu WC, Liang ZZ (2009) Numerical analysis of slope stability based on the gravity increase method. Computers

\& Geotechnics 36:1246-1258. https://doi.org/10.1016/j.compgeo.2009.06.004

Lin H, Xiong W, Cao P (2013) Stability of soil nailed slope using strength reduction method. European https://doi.org/10.1080/19648189.2013.828658

Shen J, Karakus M (2014) Three-dimensional numerical analysis for rock slope stability using shear strength reduction method. Canadian Geotechnical Journal 51:164-172. https://doi.org/10.1139/cgj-2013-0191

Shi W, Zheng Y, Tang B, Zhang L (2004) Accuracy and application range of Imbalance Thrust Force Method for slope stability analysis. Chinese Journal of Geotechnical Engineering 26:313-317 (in Chinese)

Tang HM, Yong R, Eldin ME (2016) Stability analysis of stratified rock slopes with spatially variable strength parameters: the case of Qianjiangping landslide. Bulletin of Engineering Geology and the Environment:1-15. https://doi.org/10.1007/s10064-016-0876-4

The National Standards Compilation Group of People's Republic of China (2014) GB 51016-2014 Technical code for non-coal open-pit mine slope engineering China Standard Press, Beijing (in Chinese)

Wei WB, Cheng YM (2010) Soil nailed slope by strength reduction and limit equilibrium methods. Computers and Geotechnics 37:602-618. https://doi.org/10.1016/j.compgeo.2010.03.008

Wei WB, Cheng YM, Li L (2009) Three-dimensional slope failure analysis by the strength reduction and limit equilibrium methods. Computers \& Geotechnics 36:70-80. https://doi.org/10.1016/j.compgeo.2008.03.003

Xie S, Lin H, Wang Y, Cao R, Li J (2020) Nonlinear shear constitutive model for peak shear-type joints based on improved Harris damage function. Archives of Civil and Mechanical Engineering 20:95. https://doi.org/10.1007/s43452-020-00097-Z

Yin X, Lin H, Chen Y, Wang Y, Zhao Y (2020) Precise evaluation method for the stability analysis of multi-scale slopes. SIMULATION: Transactions of The Society for Modeling and Simulation International 96(10):841-8. https://doi.org/10.1177/0037549720943274

Yong R, Fu X, Hung M, Liang QF, Du SG (2017) A rapid field measurement method for the determination of Joint Roughness Coefficient of large rock joint surfaces. KSCE Journal of Civil Engineering 22:101-9. https://doi.org/10.1007/s12205-017-0654-2

Yong R, Qin JB, Huang M, Du SG, Liu J, Hu GJ (2018a) An Innovative Sampling Method for Determining the Scale Effect of Rock Joints. Rock Mechanics and Rock Engineering 52(3):935-946. https://doi.org/10.1007/s00603-018-1675-y 
Yong R, Ye J, Li B, Du SG (2018b) Determining the maximum sampling interval in rock joint roughness measurements using Fourier series. International Journal of Rock Mechanics and Mining Sciences 101:78-88. https://doi.org/10.1016/j.jirmms.2017.11.008 

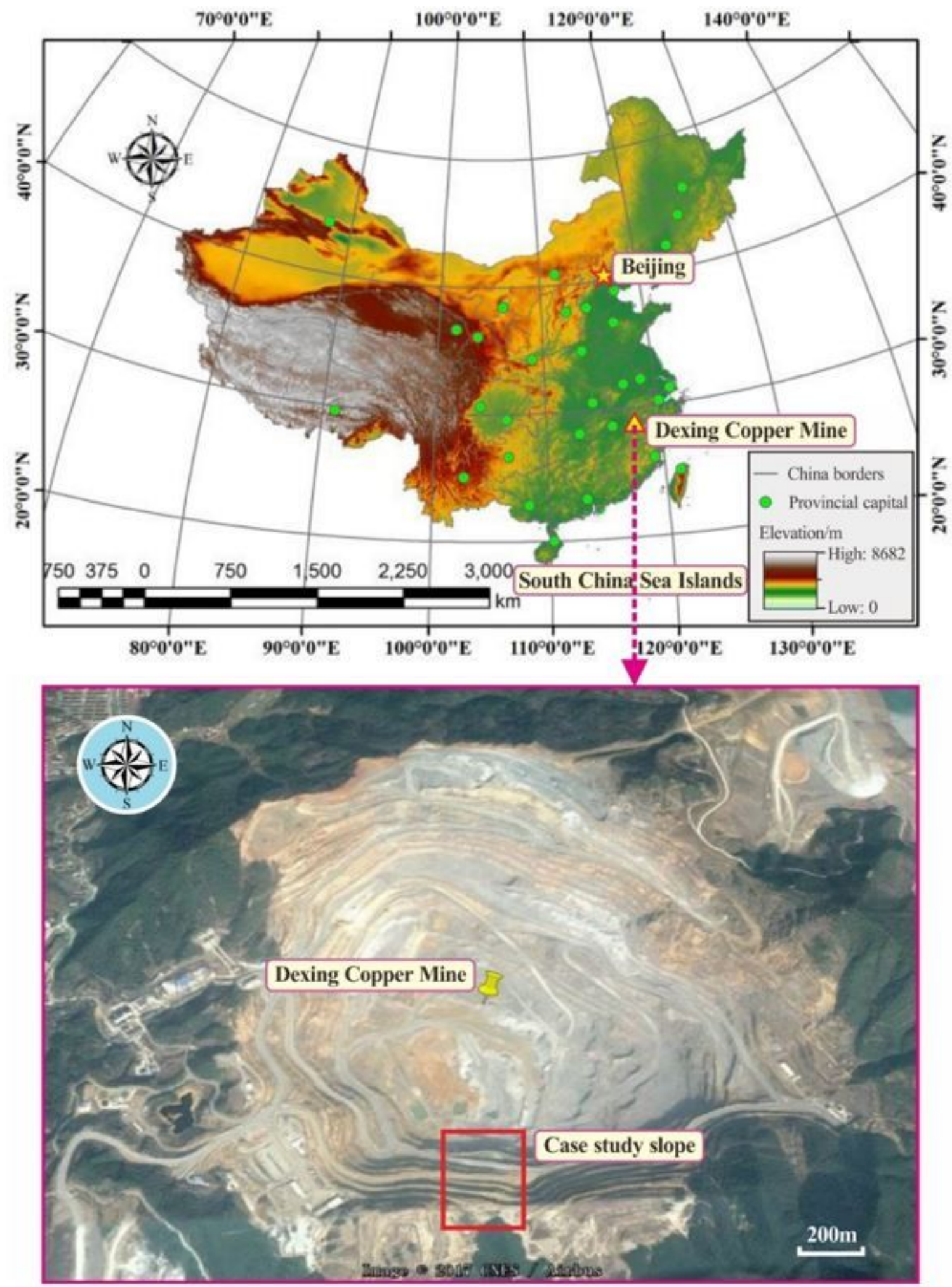

\section{Figure 1}

Location map of study area indicating case study slope location Note: The designations employed and the presentation of the material on this map do not imply the expression of any opinion whatsoever on the part of Research Square concerning the legal status of any country, territory, city or area or of its 
authorities, or concerning the delimitation of its frontiers or boundaries. This map has been provided by the authors.

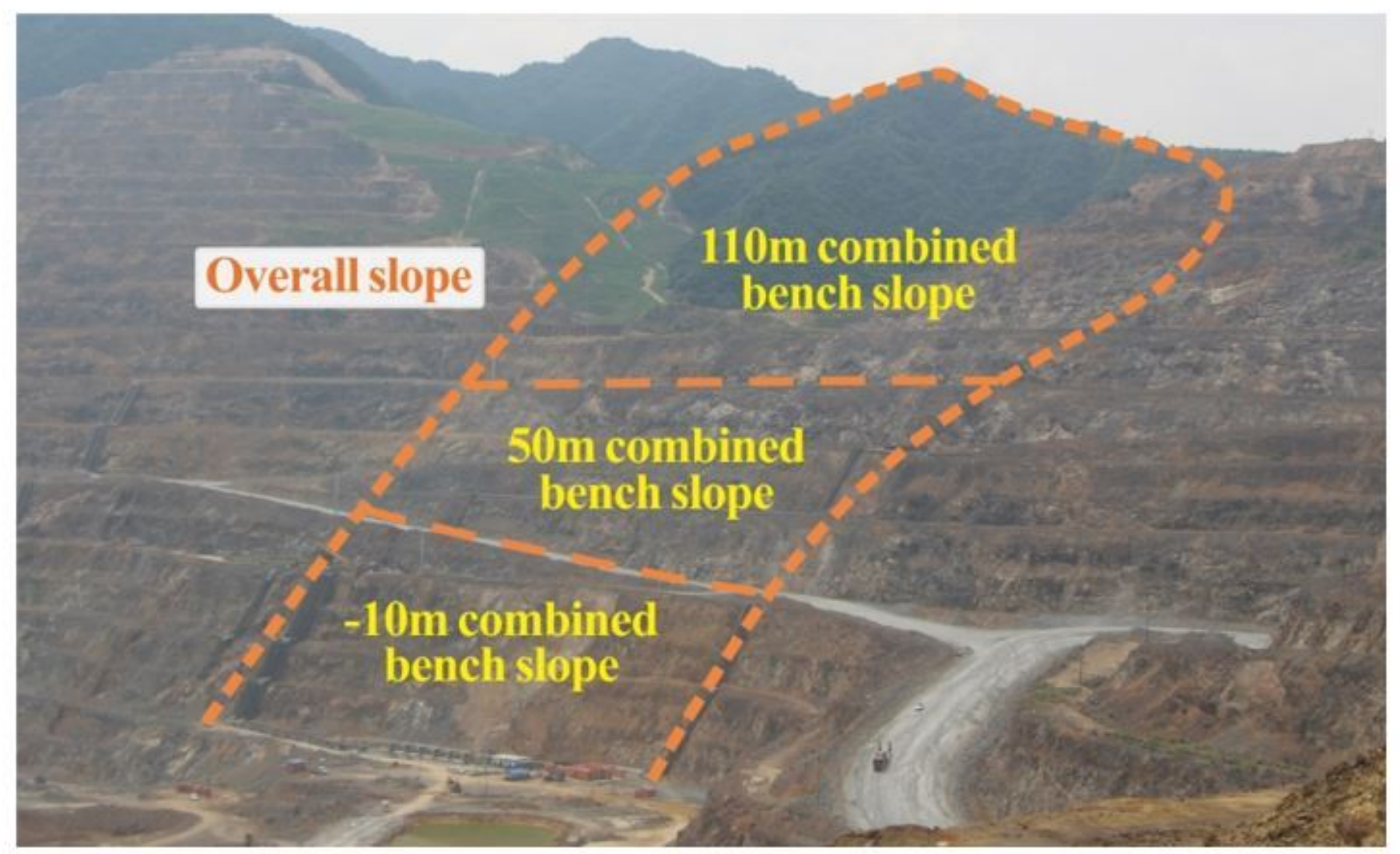

Figure 2

The photo of Yangtaowu slope indicating the overall slope and combined bench slopes 


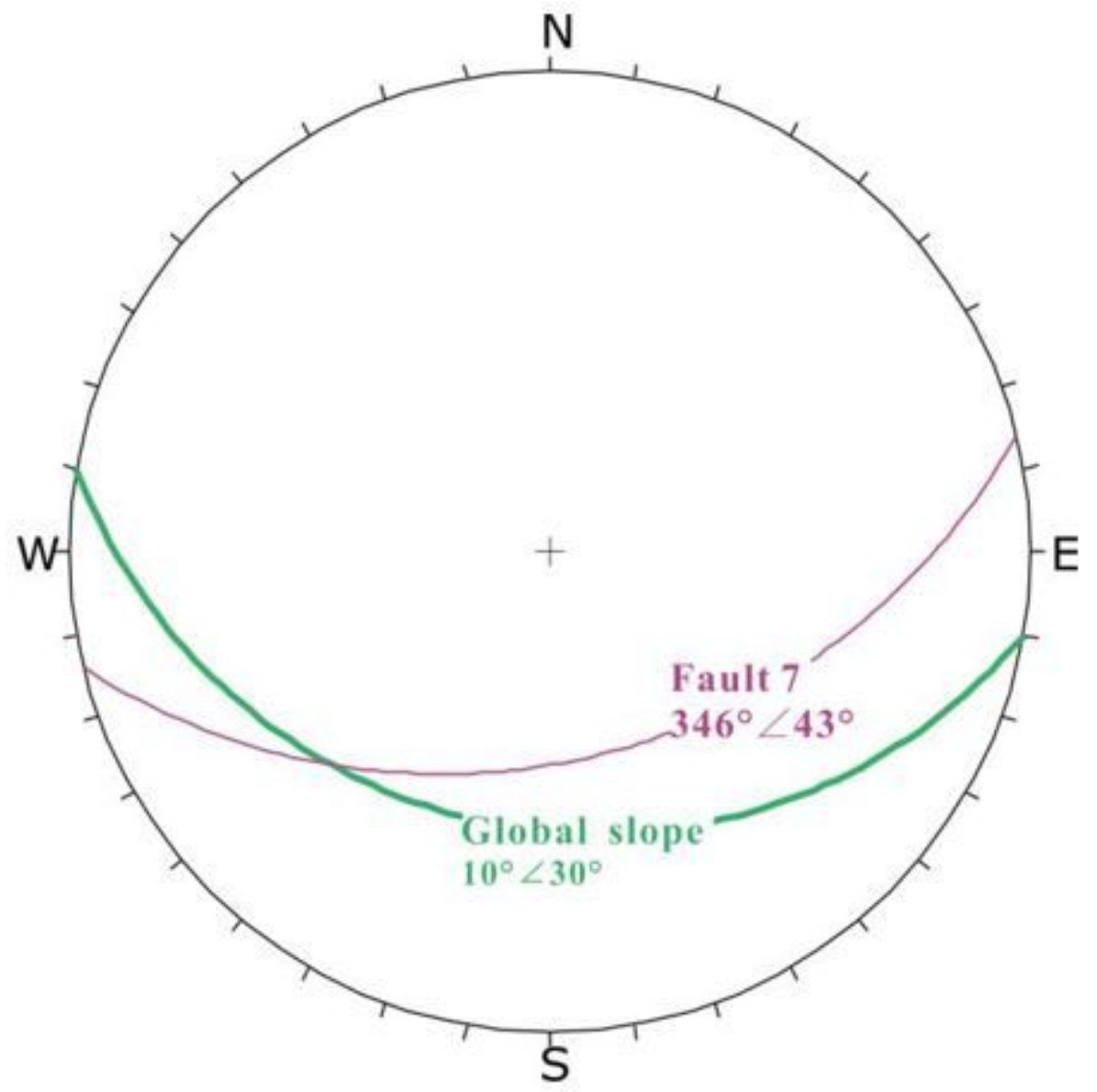

Figure 3

Stereonet of the Yangtaowu overall slope (global) 


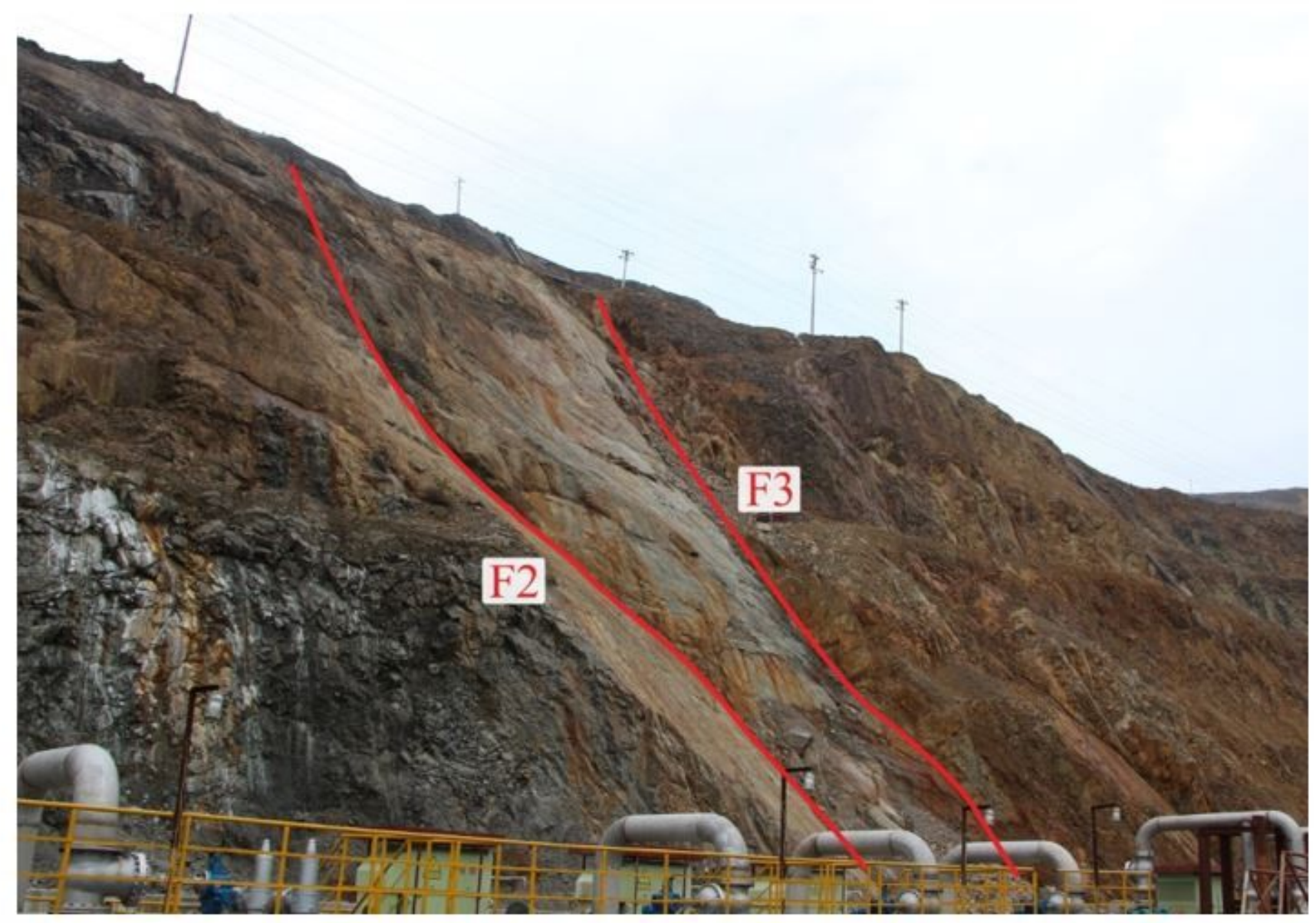

Figure 4

View of combined bench slope B (-10T) and the locations of F2 and F3 


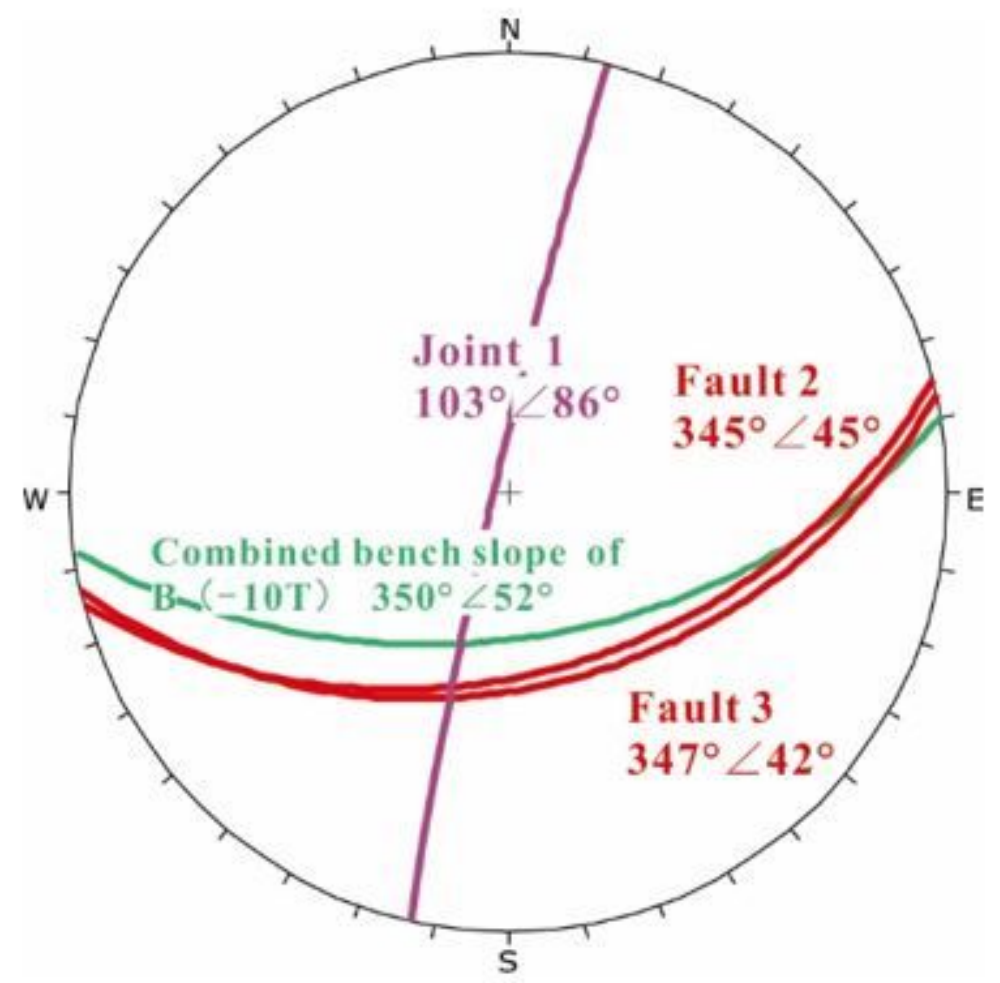

Figure 5

Stereonet of combined bench slope B(-10T) for global stability analysis 


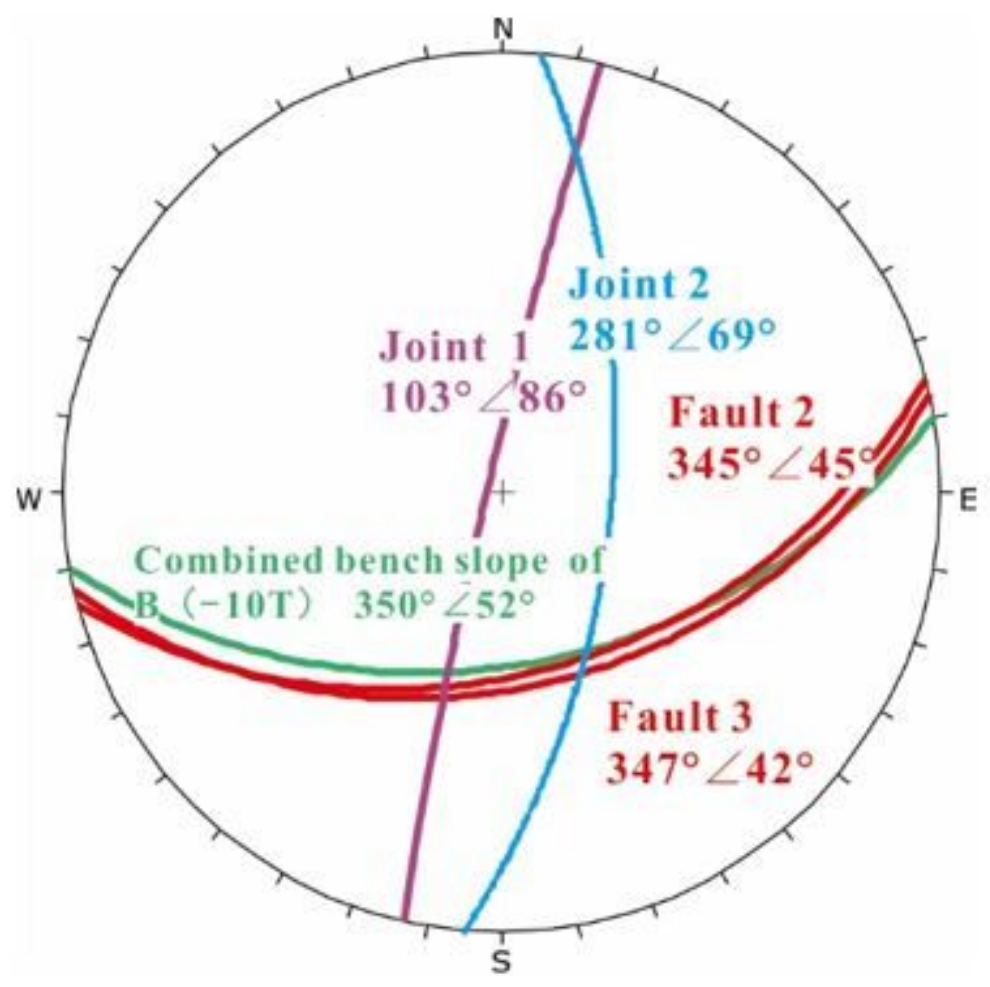

Figure 6

Stereonet of combined bench slope B(-10T) for local stability analysis

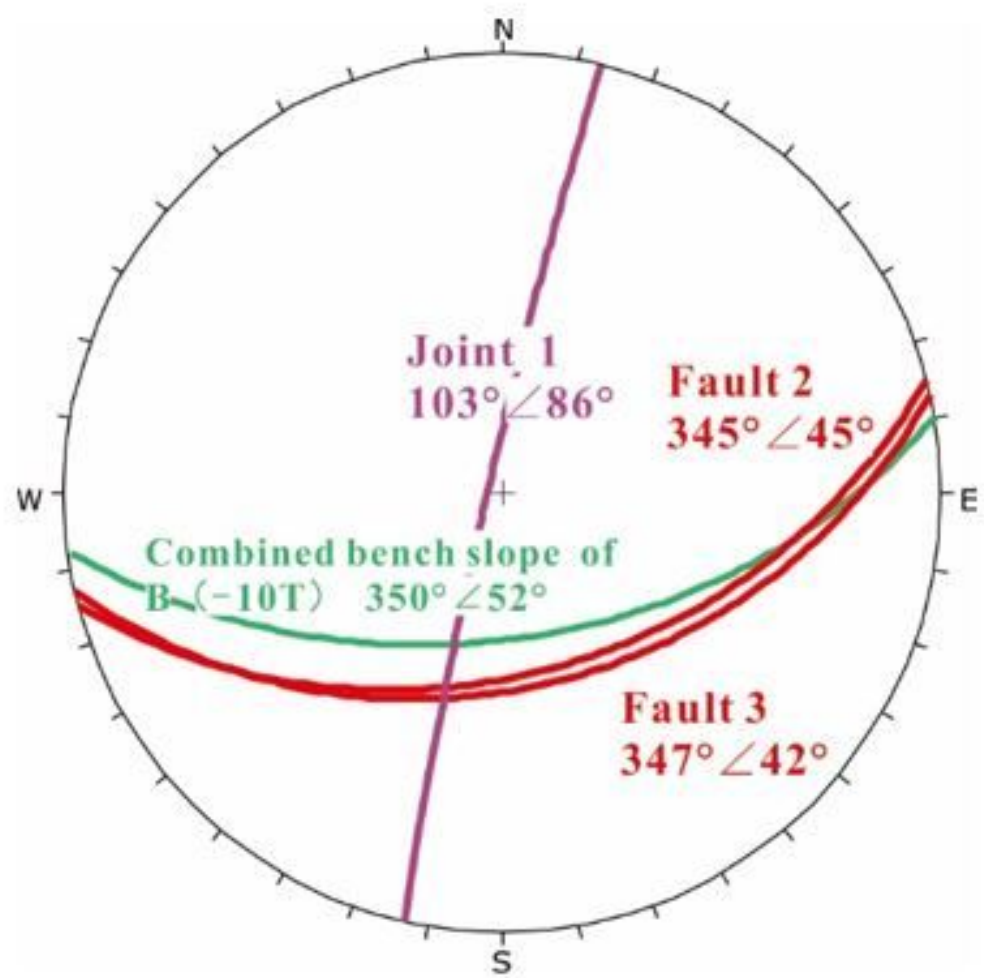


Figure 7

Stereonet of bench slopes B(-10T)-U and B(-10T)-D for global stability analysis

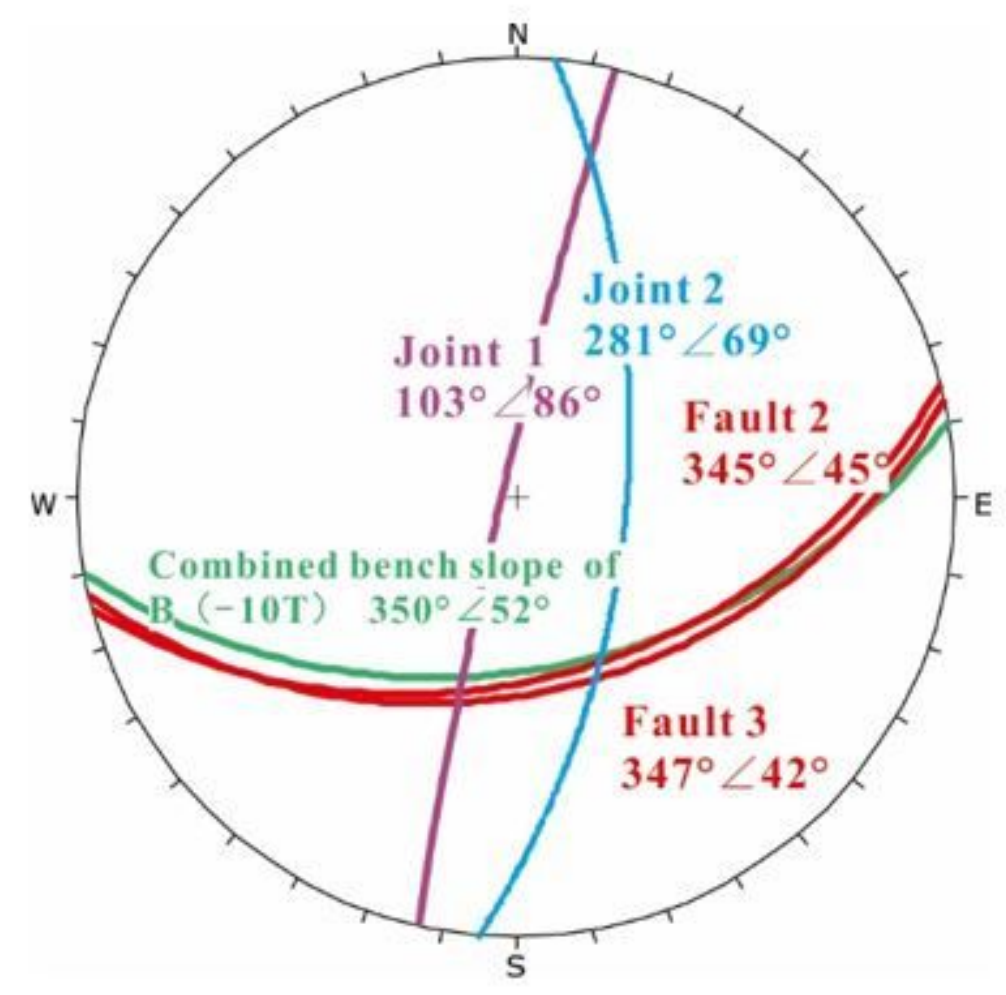

Figure 8

Stereonet of bench slopes B(-10T)-U and B(-10T)-D for local stability analysis 


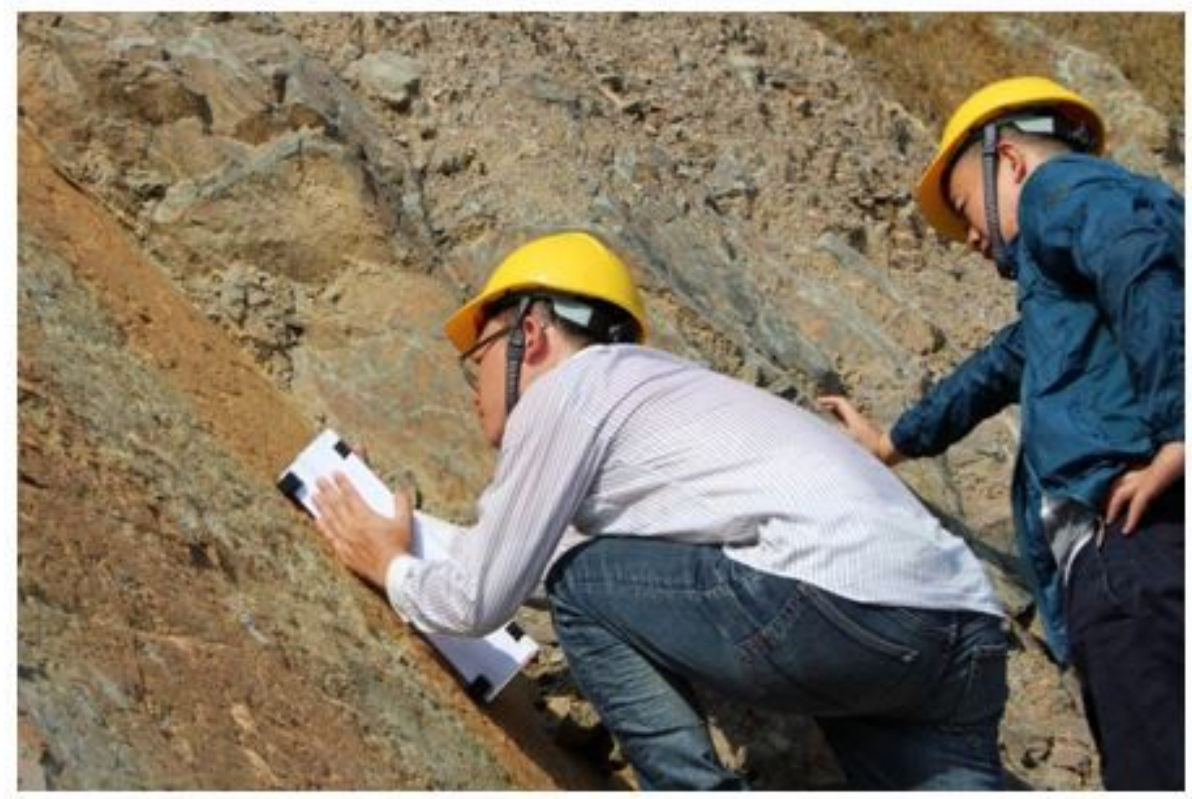

(a)

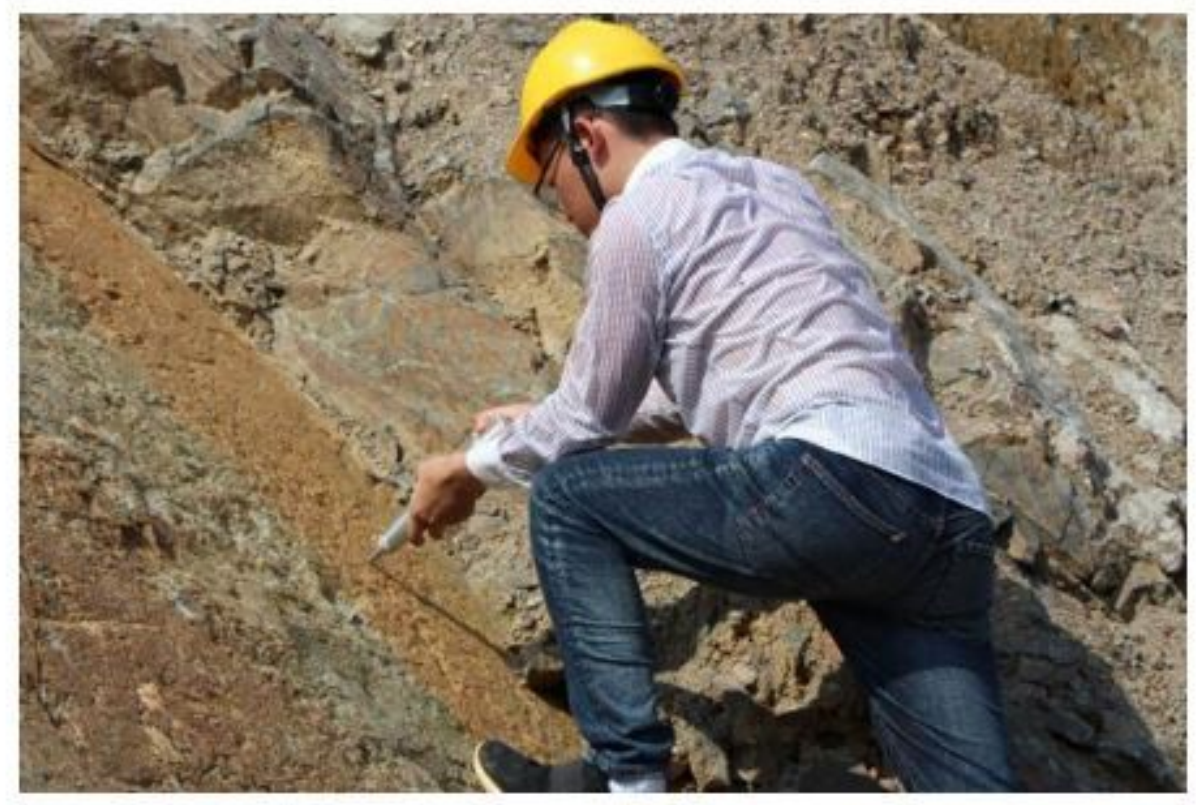

(b)

\section{Figure 9}

Measurement of sliding surface (a) rough joint profiles (b) rebound value 


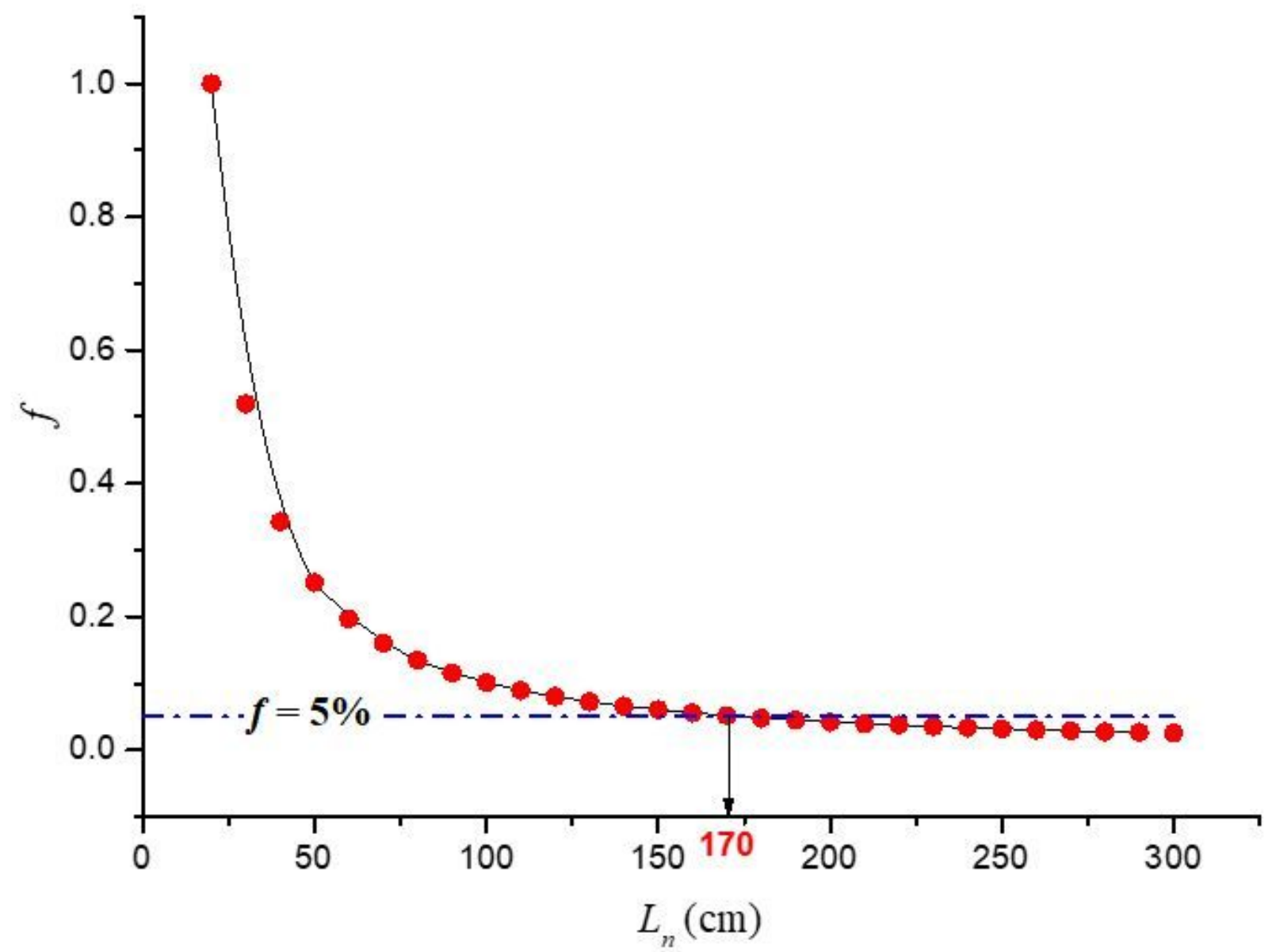

Figure 10

Ln-f relation curve of fault F2

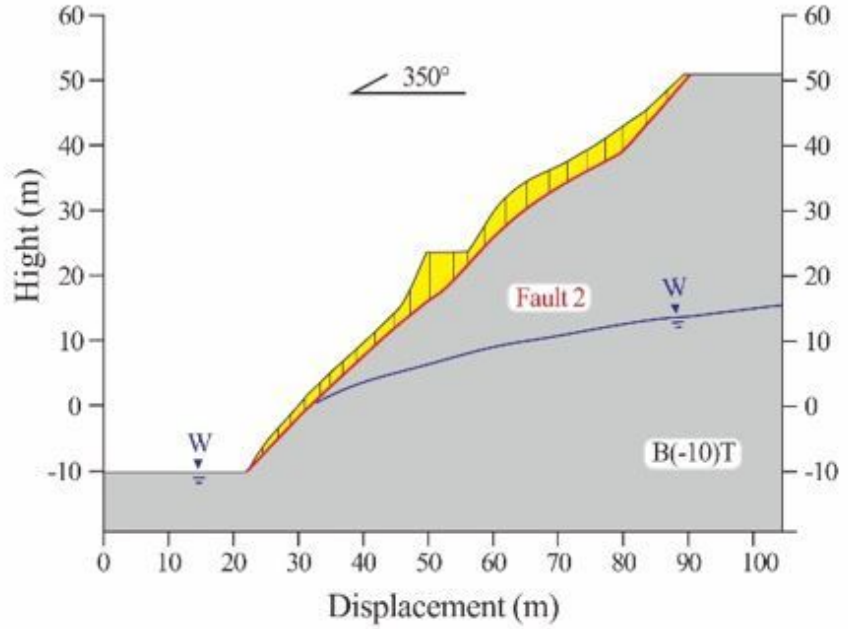

(a)

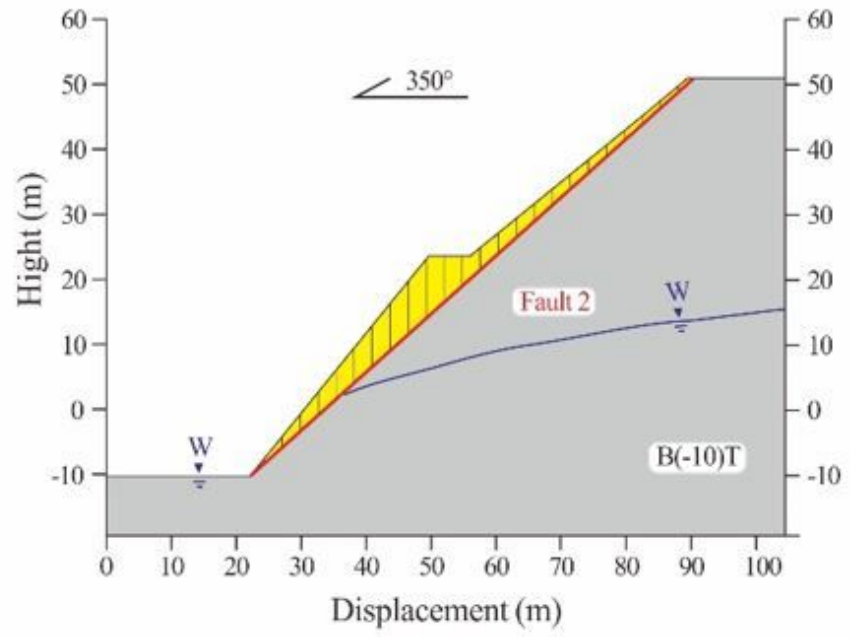

(b)

Figure 11 
B (-10T) calculation models for the first evaluation (a) Precise calculation model (b) Generalization calculation model

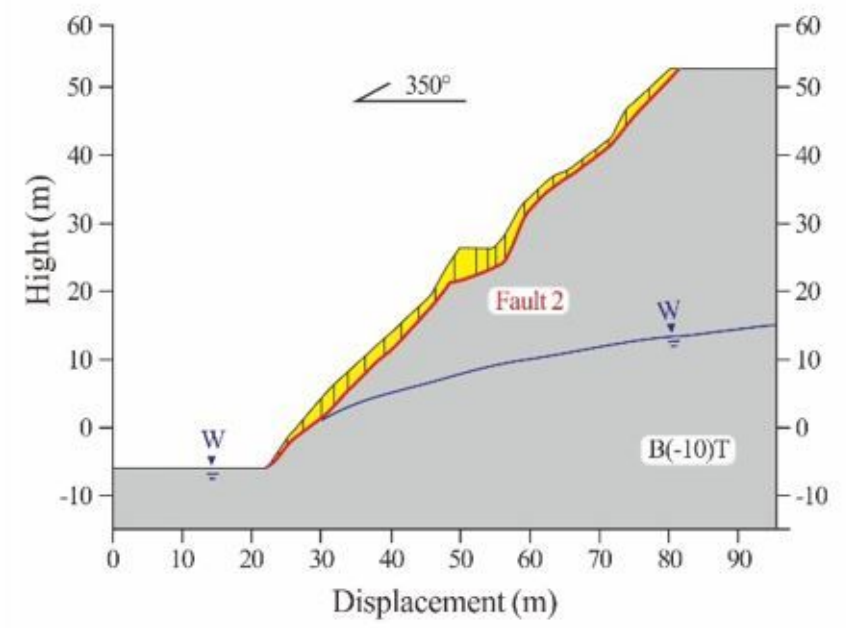

(a)

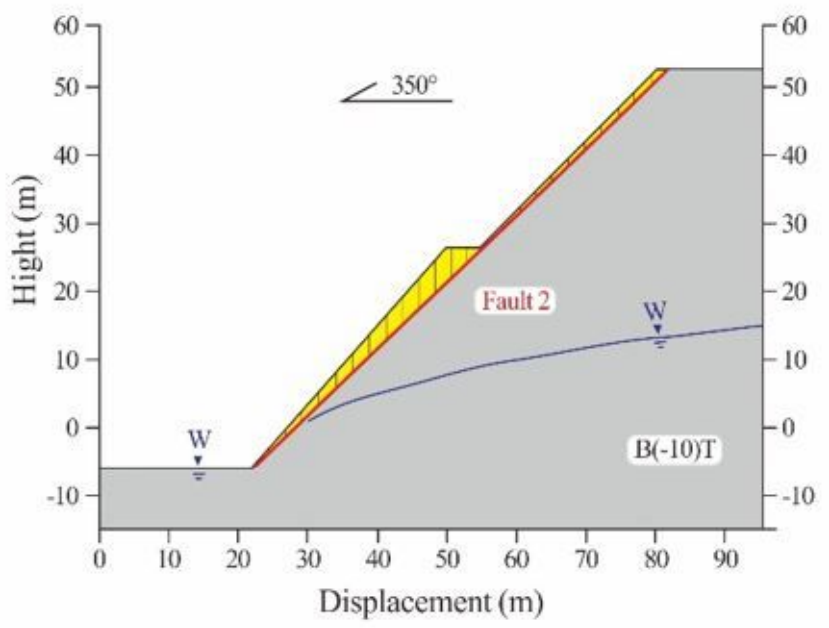

(b)

\section{Figure 12}

B (-10T) calculation models for the second evaluation (a) Precise calculation model (b) Generalization calculation model

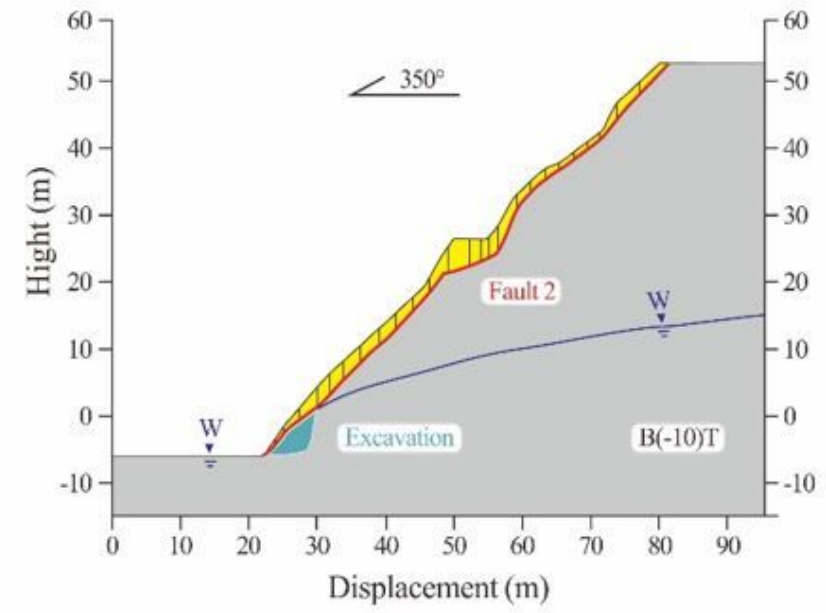

(a)

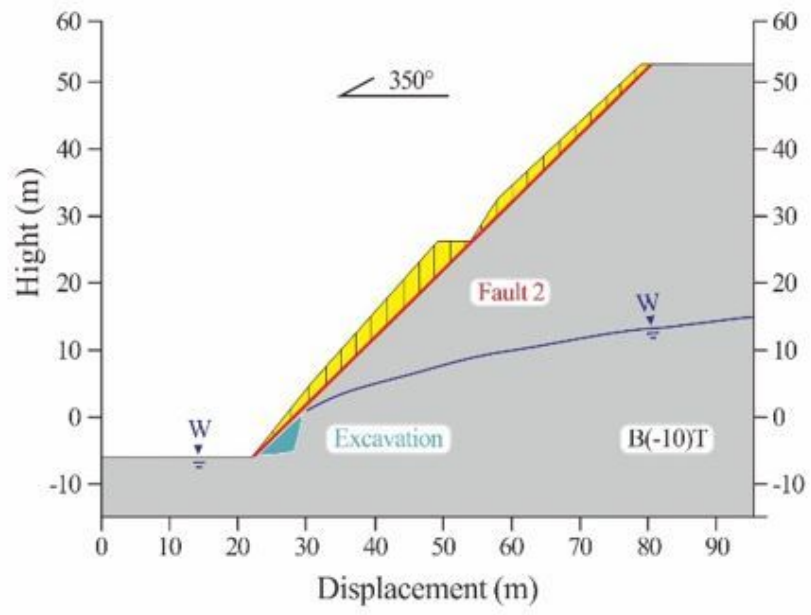

(b)

\section{Figure 13}

B (-10T) calculation models for the third evaluation (a) Precise calculation model (b) Generalization calculation model 




Figure 14

Locations of slopes B1, B2 and B

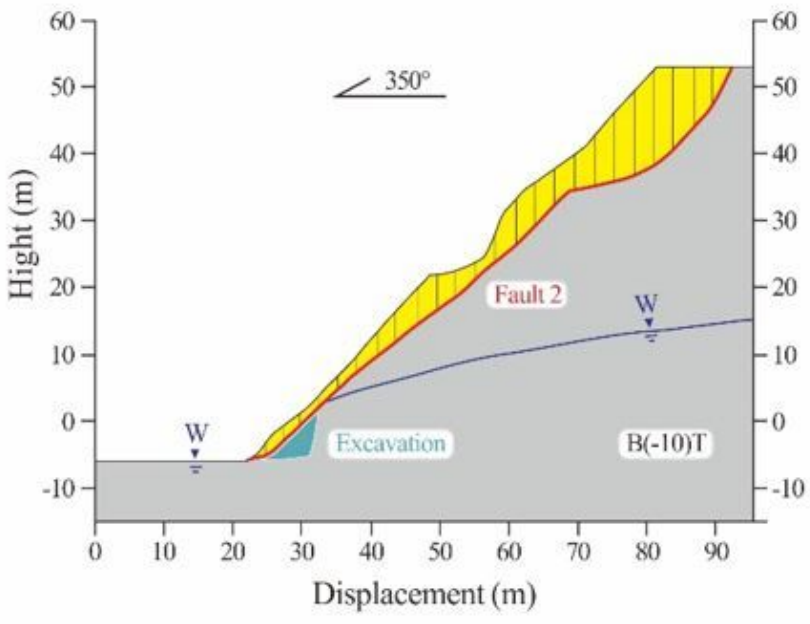

(a)

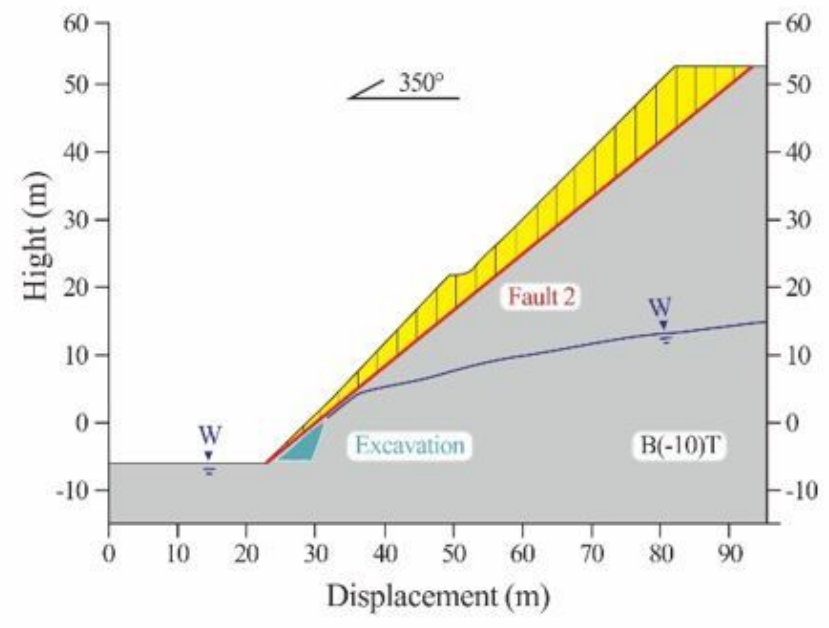

(b)

Figure 15 
B (-10T) calculation models for the fourth evaluation (a) Precise calculation model (b) Generalization calculation model 